\title{
Duplication of Inferior Vena Cava with Left Inferior Vena Cava Draining into Right Inferior Vena Cava - A Case Report
}

\author{
Nikita Jindal ${ }^{1}$, Venkata Ravi Teja Reddy Gayam² ${ }^{2}$ Richa Jindal ${ }^{3}$, Dhruv Jindal ${ }^{4}$ \\ 1, 2 Department of Radiodiagnosis, Maharishi Markandeshwar Institute of Medical Sciences and \\ Research, Mullana, Ambala, Haryana, India, ${ }^{3}$ Dayanand Medical College, Ludhiana, Punjab, India, ${ }^{4}$ All India \\ Institute of Medical Sciences (AIIMS), New Delhi, India.
}

\section{INTRODUCTION}

Double inferior vena cava is a rare anomaly with incidence rate of $0.2-3 \%$. It occurs due to non-regression of both right and left supracardinal veins during embryonic development. Here, we present a case with double inferior vena cava diagnosed in a patient who underwent routine computed tomography for abdominal pain. In our case, both right and left inferior vena cava are of same caliber and we believe that duplication of IVC in our case was a result of nonregression of anastomosis between left supra subcardinal, posterior subcardinal and intersubcardinal veins resulting in persistence of left subcardinal vein. The knowledge of this anatomical variation is clinically important during retroperitoneal surgeries and vascular and radiological interventional procedures.

Inferior vena cava anomalies are rare and incidentally found in asymptomatic patients who undergo radiological imaging for some other diseases. The reported incidence of duplicated inferior vena cava is 0.2 to $3 \%$. Among all the inferior vena cava anomalies, inferior vena cava duplication and left inferior vena cava are most commonly found.1,2

Vascular anomalies often get encountered in computed tomography (CT) scans of abdomen and pelvis obtained with contrast injection. Familiarity with these variations is essential for correct interpretation. ${ }^{3}$ Here, we present a case of duplication of inferior vena cava with left IVC draining into right IVC at upper border of L2 vertebral level.

\section{PRESENTATION OF CASE}

A 52-year-old female came to our Outpatient department with complaints of fever and pain in left flank radiating to back. On ultrasound examination, pyelonephritis with left renal abscesses with rupture of one of them was noted. Patient underwent contrast enhanced CT abdomen for further evaluation. On CECT abdomen, along with renal pathology, we also noted an incidental finding of duplicated inferior vena cava (Figs. 1(a), Fig. 2). In our case, both the common iliac veins were formed by the joining of external iliac veins and internal iliac veins at $\mathrm{S} 1$ vertebral level. These two common iliac veins did not join and were seen on either side of descending abdominal aorta. Right common iliac vein continued as right IVC whereas left common iliac continued as left IVC. 4
Corresponding Author:

Dr. Nikita Jindal,

Jindal Nursing and Maternity

Home, Water Works Road,

Mansa, Punjab-151505,

India,

E-mail: jindalnikita@yahoo.com

DOI: $10.14260 / j e m d s / 2021 / 479$

How to Cite This Article:

Jindal $N$, Gayam VR, Jindal $R$, et al. Duplication of inferior vena cava with left inferior vena cava draining into right inferior vena cava - a case report. J Evolution Med Dent Sci 2021;10(30): 2343-2345 DOI:

10.14260/jemds/2021/479

Submission 20-03-2021,

Peer Review 24-05-2021

Acceptance 31-05-2021,

Published 26-07-2021.

Copyright (c) 2021 Nikita Jindal et al. This is an open access article distributed under Creative Commons Attribution License [Attribution 4.0 International (CC BY 4.0)] 
At the level of upper border of L2 vertebra, the left IVC was seen passing anteriorly to the abdominal aorta to join the inferior vena cava on right side to form a single right sided IVC (Fig.1(b)). The two IVCs and their arched part had the same caliber. We also noted accessory renal arteries on both sides.
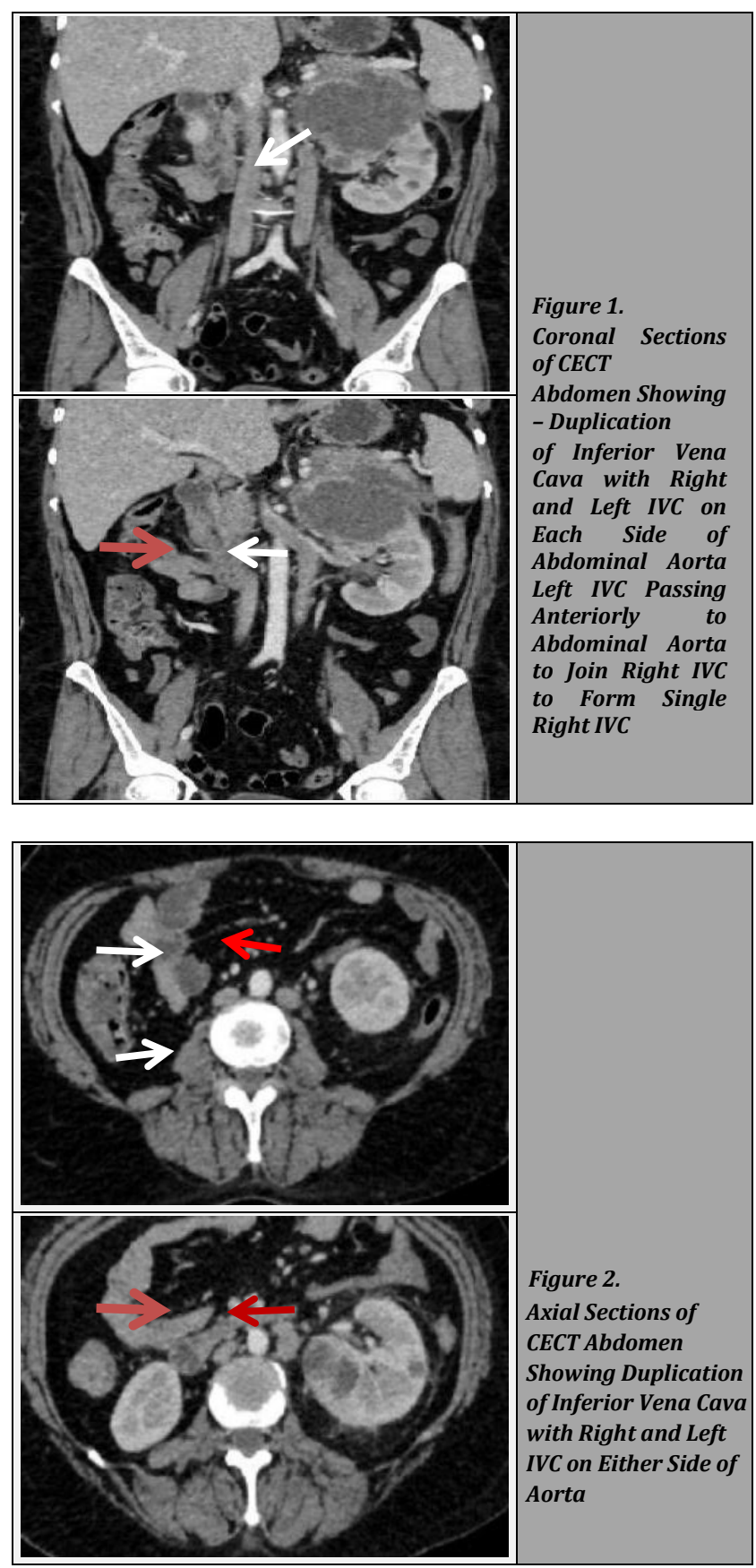

\section{DISCUSSION}

Normally, inferior vena cava develops from anterior and posterior cardinal veins and supra and subcardinal veins. ${ }^{5}$

\section{Embryology of Double Inferior Vena Cava}

Inferior vena cava is divided into four segments based on its embryological development. These segments include Hepatic, supra-renal, renal and infra-renal. IVC develops between 6th and 8th week of gestation through a series of complex anastomoses and regressions of posterior cardinal veins, subcardinal, supracardinal and vitelline veins. ${ }^{6,7}$ Intrahepatic segment of IVC develops from right vitelline vein. The prerenal segment develops from the right sub-cardinal vein and renal segment develops from sub-supracardinal anastomosis. A non-regressed segment of right supra-cardinal vein forms its post renal segment.8,9 The distal segments of posterior cardinal vein remain in pelvis to form the common iliac veins. Left subcardinal and left supracardinal vein regress completely. Any alteration in these steps lead to wide range of developmental anomalies. Non-regression of both right and left supracardinal veins during embryonic development leads to occurrence of double inferior vena cava.

In our case, the left IVC was not draining into the left renal vein, instead, it was continuing as a pre-aortic trunk to empty into the right IVC. We believe that duplication of IVC in our case was a result of non-regression of anastomosis between left suprasubcardinal, posterior subcardinal and intersubcardinal veins resulting in persistence of left subcardinal vein.

Natsis $\mathrm{K}$ et al. ${ }^{10}$ described a case of complete bilateral duplication of IVC with left IVC draining into right IVC at L2 vertebral level. Our case is similar to this case. The knowledge of this anatomical variant is important for surgical and vascular interventional procedures such as retroperitoneal lymph nodal dissection, retroperitoneal surgeries as well as for IVC filter placement to prevent pulmonary embolism. ${ }^{11}$ Phlebography is indicated by many authors as the gold standard for diagnosing duplicated inferior vena cava although it is an invasive procedure. Some authors suggested combination of ultrasound and computed tomography for adequate diagnosis.

\section{CONCLUSIONS}

Non-regression of both right and left supracardinal veins with persistence of the left suprasubcardinal, post subcardinal anastomosis during embryonic development leads to occurrence of double inferior vena cava. It has a clinical importance in retroperitoneal surgical procedures and for placement of IVC filter to prevent pulmonary thromboembolism in patients who have deep vein thrombosis and cannot be given anti-coagulants. This kind of anatomical variation should be studied with phlebography as it is capable of identifying as well as revealing the anatomy of relevant vessels. The knowledge of this anomaly plays an important role in resection of abdominal aortic aneurysms as well as in left lumbar sympathectomy procedure as it may conceal the sympathetic trunk.

Financial or other competing interests: None.

Disclosure forms provided by the authors are available with the full text of this article at jemds.com.

\section{REFERENCES}

[1] Giordano JM, Trout HH 3rd. Anomalies of inferior vena cava. J Vasc Surg 1986;3(6):924-83. 
[2] Hans SS, Gordon M. Double inferior vena cava and abdominal aortic aneurysm. J Cardiovasc Surg (Torino) 1989;26(1):76-8.

[3] Larde D, Frijol J, Belloir C, et al. Contribution of computed tomography to the exploration of congenital anomalies of inferior vena cava. J Radiol 1981;62(67):363-7.

[4] Chou CT, Yang AD, Hong YC, et al. Bilateral retrocaval ureters with IVC duplication. Abdom Imaging 2006;31(5):596-7.

[5] Sardi A, Minken SL. The placement of intracaval filters in an anomalous (left-sided) vena cava. J Vasc Surg 1987;6(1):84-6.

[6] Mayo J, Gray R, St Louis E, et al. Anomalies of the inferior vena cava. AJR Am J Roentgenol 1983;140(2):339-45.
[7] Chuang VP, Mena CE, Hoskins PA. Congenital anomalies of the inferior vena cava. Review of embryogenesis and presentation of a simplified classification. Br J Radiol 1974;47(556):206-13.

[8] Williams PL, Bannister H, Berry MM, et al. Gray's Anatomy. In: Embryology and Development. 38th edn. London: Churchill Livingstone 1995:324-5.

[9] Smith TR, Frost A. Anomalous inferior vena cava associated with horseshoe kidneys. Clin Imaging 1996;20(4):276-8.

[10] Natsis K, Apostolidis S, Noussios G, et al. Duplication of the inferior vena cava: anatomy, embryology and classification proposal. Anat Sci Int 2010;85(1):56-60.

[11] Royal SA, Callen PW. CT evaluation of anomalies of the inferior vena cava and left renal vein. AJR Am J Roentgenol 1979;132(5):759-63. 